\title{
AN ELECTRON-MICROSCOPE STUDY OF NATURALLY OCCURRING AND CULTURED CELLS OF NEISSERIA GONORRHOEAE
}

\author{
P. Novotny, J. A. Short AND P. D. Walker \\ Department of Bacteriology, Wellcome Research Laboratories, \\ Langley Court, Beckenham, Kent BR3 $3 B S$
}

\section{Plates XXX-XL}

For the development of an effective gonococcal vaccine it is likely that knowledge of virulence factors is required so that antigens of possible protective value can be defined. It is then necessary to determine whether such protective antigens are produced by gonococci cultured in vitro.

Much of the work being carried out at the present time on gonococci was stimulated by the discovery by Kellogg et al. (1963) of four different colonial types designated T1-T4. Although all the colony types derived from a single strain were virulent for human volunteers for up to 38 selective passages, only $\mathrm{T} 1$ and $\mathrm{T} 2$ colonies were able to produce the disease after several hundred passages (Kellogg et al., 1968).

Work on the gonococcus has been hampered by the lack of an animal model, since the only susceptible species appear to be man and chimpanzees (Lucas et al., 1971). Recently, however, there have been reports that claim to measure virulence by simple in-vivo procedures. Arko $(1972,1973)$ used implanted capsules in laboratory animals to cultivate gonococci in vivo and showed that the avirulent types when injected into these were cleared much faster than virulent types. The model was also useful in the study of active immunisation (Arko, 1974). Buchanan and Gotschlich (1973) demonstrated that T1 and T2 gonococci survived for longer periods than their T3 and T4 counterparts when inoculated on the chorioallantoic membrane of embryonated eggs. Bumgarner and Finkelstein (1973), although failing to support this finding, showed remarkable differences in virulence between the types on intravenous injection into 11-day-old chick embryos. In addition, experiments with human polymorphs have shown that $\mathrm{T} 1$ cells are retained to a greater extent and are more resistant to digestion than T4 cells (Thomas, Hill and Tyeryar, 1973) and that virulent cells have greater resistance to phagocytosis (Ofek, Beachey and Bisno, 1974). Human bactericidal serum (Thomas et al., 1973) or rabbit antiserum to T2 gonococci enhanced phagocytosis of virulent but not avirulent cells (Ofek et al., 1974).

Although it is possible by laboratory culture to distinguish colonies of Neisseria gonorrhoeae that are believed to be virulent, the factors responsible for virulence are far from clear. Jephcott, Reyn and Birch-Andersen (1971) and independently Swanson, Kraus and Gotschlich (1971) demonstrated that gonococci of colonial types T1 and T2 were piliate whereas those of T3 and T4 were not. As this appeared to be the most significant morphological difference between the virulent and avirulent colony types it was thought that piliation might be the factor that conferred virulence. Although in describing these appendages the term fimbriae has a prior claim over that of pili (Brinton, 1965; Duguid, Anderson and Campbell, 1966), the latter is in more general use as applied to gonococci and is used throughout the

Received 13 Nov. 1974; accepted 4 Feb. 1975.

J. MED. MICROBIOL.-vOL. 8 (1975) 
present article. Ward and Watt (1972) showed that in urethral scrapings from males with acute gonorrhoea a close association of the cocci with epithelial cells existed, and it appeared that an important factor in virulence was the ability of the cocci to attach themselves to host cell-membranes. If this ability was due primarily to pili, electron microscopy would be a valuable technique for the rapid screening of strains for virulence and for the selection of strains suitable for vaccine development.

The first experimental vaccines that were developed in our laboratory were based on the assumed importance of pili in infection. Several strains were isolated that even in tank culture were rich in pili. Although in plate cultures these strains demonstrated the usual "virulent" colonial morphology, individually they differed in the degree of piliation from those strains described in the literature. Accordingly, it was decided to use the electron microscope to compare the morphology of cultured gonococci with that of organisms occurring in urethral exudates from male patients with acute gonorrhoea. The results of this study are presented here.

\section{MATERIALS AND METHODS}

Solid media. To $100 \mathrm{ml}$ of melted GC Medium Base (Difco Manual, 1971) were added $2 \mathrm{ml}$ of defined supplement (Kellogg et al., 1963) and $2 \mathrm{ml}$ of $0.2 \%(\mathrm{w} / \mathrm{v})$ ferric nitrate, both filter-sterilised.

Liquid media. Either GC Medium (Difco formula with agar omitted) or 199 medium with riboflavin and Tween 80 omitted (Kenny et al., 1972) was used. To $200 \mathrm{ml}$ in 500 -ml conical flasks, $1.5 \%(\mathrm{w} / \mathrm{v})$ sterile sodium bicarbonate $(1.5-3.5 \mathrm{ml})$ was added before inoculation to adjust the $p \mathrm{H}$ to 7.6 .

Strains. Strains used in this study included recent isolates from a South-London VD clinic (strains labelled StG) and two strains (nos. Patl and CN6826) from a North-London clinic. The isolates were preserved by freezing in liquid nitrogen after resuspending them in culture medium containing $10 \%(\mathrm{v} / \mathrm{v})$ glycerol.

Culture procedures. Plate cultures were incubated in jars at $37^{\circ} \mathrm{C}$ with approximately $10 \%$ $\mathrm{CO}_{2}$ generated from a mixture of sodium bicarbonate, citric acid and water. The colonial morphology of primary isolates was noted as well as the results of oxidase tests and sugar fermentations (Kellogg and Turner, 1973).

Flasks containing inoculated liquid medium were shaken at $37^{\circ} \mathrm{C}$ on an orbital shaker (Kuhner, Basel, type RC-4-Sp) at 150 r.p.m. with a radius of $50 \mathrm{~mm}$. When baffled flasks were used, $10 \mu \mathrm{l}$ of polypropylene glycol 2025 (B.D.H. Chemicals Ltd, Poole, Dorset) per 200 $\mathrm{ml}$ of medium was added as antifoam.

Tank cultures were grown at $30^{\circ} \mathrm{C}$ in $2 \cdot 5$-litre volumes in a Biotec FL 103 fermenter (LKB Instruments Ltd, Croydon, Surrey). Cultures were sparged with air containing $5 \% \mathrm{CO}_{2}$ at a rate of 1 litre per min. The oxygen saturation was measured with a Biotec probe and kept between 20 and $40 \%$ by variation of the impeller speed. The $p H$ was controlled at $7 \cdot 2$ by the automatic addition of $2 \mathrm{~N} \mathrm{NaOH}$. The tank media contained polypropylene glycol 2025 as noted above.

The ratios of $\mathrm{T} 1$ and $\mathrm{T} 2$ to $\mathrm{T} 3$ and $\mathrm{T} 4$ colonies were checked by plating samples from tank cultures at appropriate intervals. With some strains, e.g., Pat1, types T1 and T2 accounted for as many as $80 \%$ of the colonies after 4-5 doublings of the bacterial mass as determined by dry weight measurement and not less than about 50\% after 15-20 doublings in a semicontinuous culture. Other strains, however, reverted more quickly and gave more than $50 \%$ $\mathrm{T} 3$ or T4 colonial types, or both, after 4-5 doublings of bacterial mass.

Collection of exudate from patients. Specimens were collected from men with symptoms of acute gonorrhoea who had had no previous treatment of any kind. To be sure that active pus was collected, the glans penis and fossa navicularis were thoroughly cleaned with swabs. The tip of a $1-\mathrm{ml}$ plastic disposable syringe, containing $0.1 \mathrm{ml}$ heparinised (40 units per $\mathrm{ml}$ ) 
physiological saline or Eagle's medium was inserted into the cleaned fossa. The urethra was milked and a few drops of pus were collected. After mixing the contents of the syringe, the suspension was treated as follows.

1. One drop was placed on a plate of GC medium and spread evenly with a loop while the plate was rotated horizontally on an electrically operated turntable.

2. One drop was placed on the surface of a freshly split piece of mica and spread evenly over its surface with the edge of another mica strip. After drying in a stream of warm air to preserve the cell structure (Hirsh and Cohn, 1960), the film was fixed by immersion in $2 \%(\mathrm{v} / \mathrm{v})$ glutaraldehyde in $0.01 \mathrm{M}$ phosphate buffer, $p \mathrm{H} 7 \cdot 4$, at $4^{\circ} \mathrm{C}$ overnight. The film was then thoroughly washed in distilled water and processed for replication.

3. One drop was spread over a glass slide, then dried in a stream of warm air and Gramstained.

4. To the remainder, $0.01 \mathrm{M}$ phosphate-buffered $2 \cdot 5 \%(\mathrm{v} / \mathrm{v})$ glutaraldehyde, $p \mathrm{H} 7 \cdot 4$, was added to give a final concentration of $2 \%$ glutaraldehyde (Sabatini, Bensch and Barrnett, 1963). After fixation overnight at $4^{\circ} \mathrm{C}$ the suspension was centrifuged and the sediment was negatively stained or embedded for sectioning.

Collection of urine. After obtaining the sample of exudate as described, the patient was asked to pass the first portion of his urine into a 1 -oz. vial containing buffered $8 \%(\mathrm{v} / \mathrm{v})$ glutaraldehyde so that the final concentration of glutaraldehyde in the urine was $2 \%$. The sample was stored at $4^{\circ} \mathrm{C}$ overnight, then spun. The sediments were examined by either negative staining or thin sectioning.

Tissue-culture experiments. Human amnion-cell monolayers were grown in the absence of antibiotics in petri dishes or on strips of mica in Eagle's basal medium containing $10 \%$ (v/v) foetal calf serum and 0.02M Hepes buffer. These were supplied by Dr A. Whitaker, Department of Virology, Wellcome Research Laboratories. They were over-layered as described by Swanson (1973) with gonococci of strain no. CN6826 of the appropriate colonial type suspended in the growth medium to an approximate concentration of $10^{8}$ c.f.u. per $\mathrm{ml}$. After incubation for $2 \mathrm{~h}$ at $37^{\circ} \mathrm{C}$, the monolayers were washed 10-15 times with the growth medium and fixed with $2 \%(\mathrm{v} / \mathrm{v})$ glutaraldehyde in $0 \cdot 1 \mathrm{M}$ phosphate buffer, $p \mathrm{H} 7 \cdot 2$, containing $0.2 \mathrm{M}$ sucrose for $30 \mathrm{~min}$. at $+4^{\circ} \mathrm{C}$. The specimens were stained with Giemsa and in addition replicas were made for examination by electron microscopy. In serum-inhibition experiments the gonococci were pretreated with antisera to type-T2 or -T4 cells for $30 \mathrm{~min}$. at $37^{\circ} \mathrm{C}$.

Preparation of antiserum. By selective subculture, GC plates containing greater than $95 \%$ of the appropriate colonial type of $N$. gonorrhoeae strain no. CN6826 could be produced. The growth from T2 or T4 colonies was harvested into sterile saline and the opacity was adjusted to that of Brown's tube 8 (Wellcome Reagents); $0 \cdot 1 \%(\mathrm{v} / \mathrm{v})$ formalin was added and the mixture was incubated at $37^{\circ} \mathrm{C}$ for $18 \mathrm{~h}$. Type-T2 suspensions were seen to contain large amounts of pili when observed by negative staining, and type-T4 suspensions contained no pili. The appropriate formolised suspension was absorbed with $2 \%(w / v)$ potash alum at $p \mathrm{H} 6$ and the vaccine was used to immunise rabbits. The rabbits received two doses of $2 \mathrm{ml}$ of the vaccine 6 weeks apart and were bled 14 days after the second injection.

Preparation of free endotoxin. All manipulations were performed at $4^{\circ} \mathrm{C}$. Cultures were centrifuged at $3000-10,000 \mathrm{~g}$ to sediment whole or partially lysed bacteria, pili and large endotoxin globules or "blebs". Small blebs remaining in the supernate were obtained by centrifuging at $48,000-110,000 \mathrm{~g}$. Three centrifugal washings at this speed resulted in a preparation consisting almost exclusively of free endotoxin and containing few if any pili. Another fraction of free endotoxin contaminated with pili could be obtained from the first sediment by fractionation in a linear $5-40 \%(w / v)$ sucrose gradient in $1 \mathrm{M} \mathrm{NaCl}$. The sediment, resuspended in $1 \mathrm{M} \mathrm{NaCl}$ was layered on the gradient and spun down at about $400 \mathrm{~g}$ for 30-45 min. The first water-clear layer contained mainly pili and small endotoxin blebs. The second dense layer contained endotoxin blebs of mixed sizes and plasmamembranes. The bottom phase consisted of whole cells, fragments of bacteria and aggregates of pili. 
The toxicity of free endotoxin was determined by injecting intravenously $0 \cdot 1-\mathrm{ml}$ volumes of 10-fold dilutions of each preparation into groups of ten 11-day-old embryonated eggs (commercial White Leghorn "Kimber" eggs) incubated at $37^{\circ} \mathrm{C}$. Deaths were recorded after $24 \mathrm{~h}$ and the results submitted to parallel line probit analysis.

Pyrogenicity was determined by injecting intravenously $2-3-\mathrm{ml}$ volumes of dilutions of preparations into rabbits of $2.5-3.0 \mathrm{~kg}$ and recording rectal temperatures for $3-4 \mathrm{~h}$. Pyrogenfree physiological saline was used as control.

3-Deoxyoctulosonate $(K D O)$ in acid $(0 \cdot 1 \mathrm{~N} \mathrm{HCl})$ hydrolysates of samples of free endotoxin was determined by the method of Elbein and Heath (1965) and the chromogen compared with that obtained with a synthetic specimen prepared according to Ghalambor, Levine and Heath (1966).

\section{Electron microscopy}

Negative staining. A sample of the material to be examined was suspended in distilled water and mixed with an equal volume of $3 \%(w / v)$ sodium phosphotungstate, $p H 7 \cdot 2$. A drop of this mixture was placed on a 400-mesh carbon-formvar coated grid. After removal of excess fluid with the edge of a filter paper, the grid was allowed to dry in air and was then examined in a Philips EM200 or EM300 electron microscope at 60 or $80 \mathrm{kV}$ respectively. Some samples were washed thoroughly with distilled water before negative staining to remove culture medium or fixative.

Sectioning. After overnight fixation in phosphate-buffered $2 \%(\mathrm{v} / \mathrm{v})$ glutaraldehyde (Sabatini et al., 1963) as described, the suspension was centrifuged, washed once in $0.01 \mathrm{M}$ phosphate buffer, $p \mathrm{H} \mathrm{7.3}$, and suspended in fixative (Palade, 1952) for $1 \mathrm{~h}$ at $4^{\circ} \mathrm{C}$. Whole cultures were fixed by the method of Kellenberger, Ryter and Séchaud (1958).

After fixation by either of these two methods, the suspension was centrifuged, the sediment dehydrated in ethanol and embedded in Araldite (Ciba, Ltd) (Glauert and Glauert, 1958). Sections were cut on an LKB ultratome (LKB Instruments Ltd, Croydon) and mounted on 200-mesh formvar-coated grids. Before examination, some sections were stained with $2 \%(w / v)$ uranyl acetate for $10 \mathrm{~min}$. and then with Reynolds' (1963) lead citrate for $5 \mathrm{~min}$.

Replication. After thoroughly washing the fixed mica film with distilled water, a replica was made with carbon-platinum electrodes in an Edwards E6 coating unit at an angle of approximately $30^{\circ}$ (Bradley, 1954). The replica was scored into 2-mm squares and separated from the mica by floating on $70 \% \mathrm{H}_{2} \mathrm{SO}_{4}$ for $1 \mathrm{~h}$, washed with distilled water, treated with sodium hypochlorite solution ( $15 \%$ available chlorine) for $1 \mathrm{~h}$, and finally given three $15-\mathrm{min}$. washes with distilled water. Cleaned replicas were placed on uncoated 400-mesh copper grids.

Freeze-etching. Samples were freeze-etched in a Balzers $360 \mathrm{M}$ freeze-etching plant (Balzers A. G., Lichtenstein) by the method of Moor et al. (1961). The table temperature was $-100^{\circ} \mathrm{C}$ and the knife temperature $-150^{\circ} \mathrm{C}$. An etching time of $1 \mathrm{~min}$. was employed and the shadowing angle used on the replicas was approximately $33^{\circ}$. Replicas were cleaned and mounted as described above.

\section{RESULTS}

\section{Studies on cultures of gonococci obtained from urethral exudates}

Plates of GC medium were preferred to Thayer-Martin medium containing antibiotics because it was possible with the former to distinguish the colonial morphology of gonococci in primary cultures and to determine the ratio of their colonial types. Twenty-eight samples from patients with acute gonorrhoea were thus examined and gonococci were detected in them all.

There was a preponderance of gonococci on the plates and few, if any, colonies of other aerobic micro-organisms (mainly micrococci, Escherichia 
coli or Streptococcus faecalis). From six patients, pure cultures of gonococci were obtained on GC plates; this indicates that the precautions used for taking the pus prevented contamination and that the pus originated from acutely infected mucosa.

Colonies from primary cultures were predominantly of types $\mathrm{T} 1$ or $\mathrm{T} 2$ or both. Two specimens gave rise to T2 colonies exclusively. In general, T3 colonies were few in number although one sample gave rise to about $10 \%$ of these. T4 colonies were not obtained in primary cultures.

To obtain highly piliate strains, several colonies were marked on each plate and a sample of each was examined by negative staining for the presence of pili. Although pili were present in all colonies, their number varied greatly. Several strains were obtained that remained highly piliate on subsequent subcultures (fig. $3 a$ ) whilst others became less piliate on subculturing. We have not found a procedure for the selection of stable highly piliate strains. In most cultures grown on agar or in liquid medium from selected colonies, the pili dissociated from cells and were found in bundles of various sizes as described by Jephcott et al. (1971). When cells with pili attached were found, bundles of pili were seen to protrude from one or several areas of the cell. In some strains the concentration was very high (more than 100 pili per cell) and they had emerged at or near the septum (fig. $1 a$ and $b$ ). On less markedly piliate cells, the pili were solitary. Even distribution (fig. $5 c$ ) was rare, and heavy piliation evenly distributed around the cell, as seen with classical fimbriae in $E$. coli, could not be demonstrated.

The mean centre-to-centre distance between pili in bundles measured on negatively stained specimens was $5.8 \mathrm{~nm}$ and this is in agreement with the value obtained by Jephcott et al. (1971). The average thickness of individual pili was difficult to determine but was about $4.5 \mathrm{~nm}$. There appeared to be no difference in the thickness of pili from different strains. The length typically exceeded $6 \mu \mathrm{m}$ and was variable. The commonest was designated pilus $a$; according to Brinton's nomenclature (1965) these pili could be classified as type II or-in view of their length-type III. They showed no tendency to form constant-angle layered crystal aggregates.

Three strains (nos. CN6826, Pat1, StG22) gave rise to another fibrillar structure which in negatively stained specimens from liquid cultures or plates differed in appearance from that of pilus $a$ (fig. 2a). These structures were usually bent and segmented as if composed of shorter units. Thickness was variable, but in general was about $30 \%$ less than that of pili $a$ and some micrographs (fig. $2 b$ ) showed these fibrils as a continuation of normal pili. Because it is not yet clear whether they are structurally related to pili $a$ or represent a completely different entity, they have been called pili $b$. Similar structures were seen in the urine of a male patient with gonorrhoea (fig. $2 c$ ).

In cultures of several strains, a third type of pilus was observed. Such pili never occurred in aggregates and often had a small knob at one end (fig. $7 a$ ). In all other respects they resembled pili $a$ and have been called pili $c$. One strain could produce both type- $a$ and type- $c$ pili, which could be distinguished serologically (Turner and Novotny, 1974; Novotny and Turner, 1975). 
In some cultures and in the preparations of free endotoxin described below, another morphological unit could be distinguished. This consisted of short bars which were always agglutinated together (fig. $7 a$ ); their individual morphology was difficult to ascertain. Similar structures have been seen in cultures and free endotoxin preparations of Bordetella pertussis.

\section{Observations on gonococci in sections and replicas prepared directly from exudates}

Frequency of occurrence of pili. In ultrathin sections of fixed pus or urine sediments, free cocci and cocci inside host cells, usually polymorphs, were seen without difficulty. The organisms had well preserved and organised surface layers (fig. $4 a-d$ ). Pili, however, were rarely seen, and it was evident that the number of piliate cells in pus was negligible in comparison with the number of pili seen in sections of cultured gonococci (fig. $3 b$ ). When fixed smears of pus were examined for evidence of pili by the replica technique a similar low frequency of pili was observed. The replica technique used was sensitive enough to detect individual pili in bundles in cultured gonococci (fig. $5 a$ ) as well as single pili in pus (fig. $5 b$ ). The ratio of non-piliate to piliate cells in seven replicas of pus in which sufficient numbers of cocci were present was about 18:1 (the table), although this varied among samples of pus. Bundles of pili $a$ similar to those seen in primary cultures and subcultures (figs. 1 and $3 a$ ) were never seen in samples of pus.

\section{Studies on the organisation of surface layers}

Naturally occurring gonococci. In describing the organisation of the gonococcal cell wall the nomenclature de Petris (1967) proposed for $E$. coli has been used (fig. 12). The naturally occurring gonococci were predominantly smooth. In some sections, the outermost layer of the cocci was homogeneous and thick, and the laminar structure was not distinct (fig. 4a). The whole layer was limited by a comparatively denser part which could have concealed the trilaminar $L$ layer. From the inner side it was demarcated by a very dense layer

TABLE

Ratio of morphologically different gonococci present in seven positive replica preparations from different samples of pus from male patients with acute gonorrhoea. Organisms occurring in clusters were not included

\begin{tabular}{ccc}
\hline $\begin{array}{c}\text { Number of } \\
\text { cocci having } \\
\text { one or } \\
\text { more pili }\end{array}$ & $\overbrace{\text { with fuzzy }}^{\text {coat }}$ & $\begin{array}{c}\text { without fuzzy } \\
\text { coat }\end{array}$ \\
\hline 73 & 973 & 331 \\
\hline
\end{tabular}

Ratio of piliate : non-piliate cells $=73: 1304$. 
corresponding to the murein-containing $\mathrm{g}_{2}$ layer. The electron-transparent $\mathrm{g}_{1}$ layer, which usually delineates the $g_{2}$ layer from the $L$ layer, was either very thin or not visible. In other sections, however, there was a well-characterised dense $l_{1}$ layer which was separated from a less dense and thinner $l_{3}$ layer by an electron-transparent $l_{2}$ layer (fig. $4 b$ ). In such sections the thickness of the whole $L$ layer was about $8.5 \mathrm{~nm}$. Between the $\mathrm{L}$ and $\mathrm{G}$ layers there was a dark, homogeneous structure-the periplasmatic space (P). In a large majority of sectioned cocci the layers were parallel; only occasionally were they seen to have a finely lobate L layer (fig. $4 d$ ), but even here the other layers were parallel. The $\mathrm{G}$ layer was separated from the trilaminar plasma-membrane by a distinct rather thin $(c .2 \mathrm{~nm}) \mathrm{M}$ layer. The whole surface structure in natural cocci was, therefore, quite thick-about $30 \mathrm{~nm}$, of which some $23 \mathrm{~nm}$ was the cell wall.

Almost all naturally occurring gonococci had a fuzzy coat outside the wellorganised cell-wall layers. It was well preserved on cocci inside as well as outside the phagocytes, and sometimes extended far out from the organisms (fig. $4 b$ and $c$ ). The average thickness of this was about $25 \mathrm{~nm}$. In replicas it had sloughed off the surface of the cocci to lodge in the angle between the cell and its support (fig. $9 a$ and $d$ ), presumably as a result of drying and fixing of the smears.

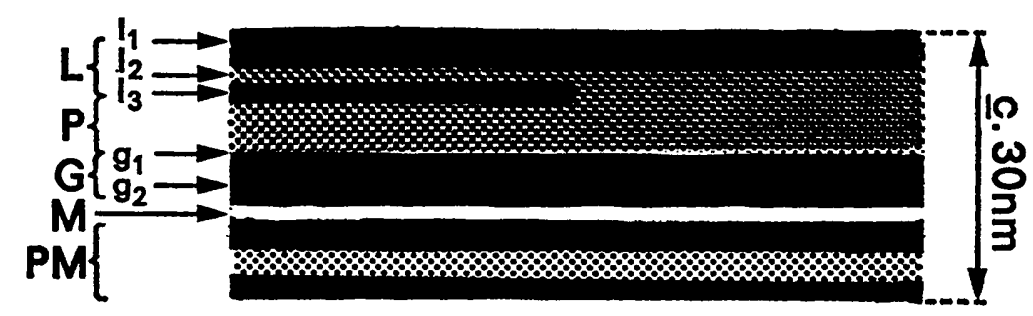

Pus

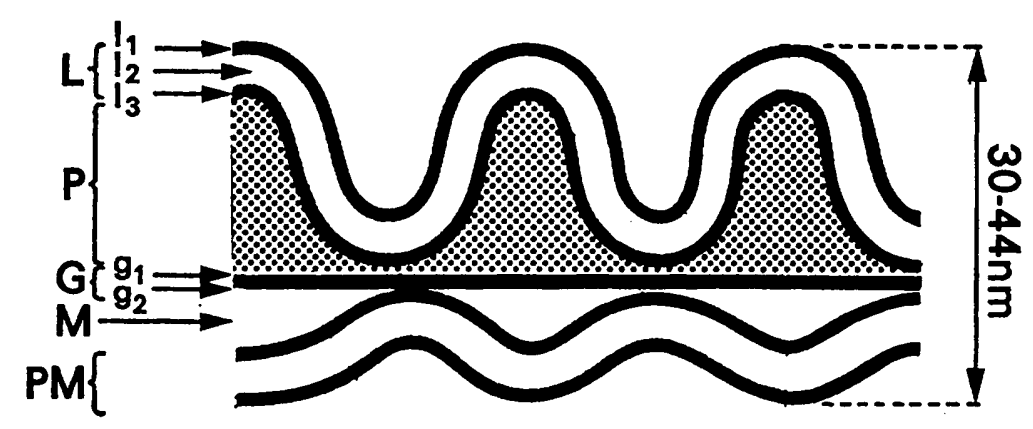

Culture

Fig. 12. Scheme of laminar structure seen in sections of gonococci from pus and from cultures and labelled according to the nomenclature of de Petris (1967). In pus, the trilaminar L-layer structure was often not perceptible. 
Cultured gonococci. All cultured gonococci from GC plates or from liquid media, when examined by the replica technique, were seen to have a rough surface (fig. 5a). In ultrathin sections the surface was crumpled, and this resulted in lobation and disorganisation of the cell-wall layers. The $L$ layer was thinner (about $6 \mathrm{~nm}$ ) and distinctly trilaminar, with the $l_{1}$ and $l_{3}$ layers of equal thickness and lobate (figs. $3 b, 7 b-e$ ). It appeared as if there was too much $\mathrm{L}$ layer for the surface area of the coccus.

The $\mathrm{g}_{2}$ layer was usually smooth, with an average thickness of about $3.6 \mathrm{~nm}$ and never as thick as that observed in natural cocci (mean thickness $4.3 \mathrm{~nm}$ ). In almost all cultured cocci the $\mathrm{g}_{1}$ layer was well preserved. The $\mathrm{G}$ layer did not follow the contour of the $L$ layer or the plasma-membrane, which was also lobate. The space between the convoluted $\mathrm{L}$ layer and the $\mathrm{g}_{1}$ layer was considerably less dense than that present in cocci from pus-indeed it sometimes appeared empty.

The $\mathbf{M}$ layer was of variable thickness since the plasma-membrane and the $\mathrm{L}$ layer were lobate. In areas of cross-wall completion it could be remarkably thick (up to $24 \mathrm{~nm}$-see fig. 7 c).

The total thickness of the surface layers of cultured gonococci measured normal to the tangent was as much as $44 \mathrm{~nm}$. The fuzzy outer coat, clearly seen on naturally occurring organisms, was not so evident but occasionally visualised in cultured cells.

\section{Tissue-culture experiments}

These experiments confirmed the results reported by Swanson (1973) that T2 cells adhered much more than did T4 cells to human amnion cells, and some replicas confirmed that pili appeared to mediate the adhesion (fig. 11e). In other examples, however, there appeared to be direct contact between the surfaces of the amnion cells and the cocci (fig. 11d). In serum-inhibition experiments, organisms pre-incubated with antiserum against $\mathrm{T} 2$ cells did not adhere whereas those incubated with antiserum against $\mathrm{T} 4$ cells were unaffected.

\section{Studies on free endotoxin}

In primary cultures and subcultures, liberation of surface layers as blebs of various shapes and sizes was observed. Similar structures were described by Kraus and Glassman (1974). These particles correspond to the definition of free endotoxin (Crutchley, Marsh and Cameron, 1967). Thus, when isolated from cultures of $N$. gonorrhoeae, they were highly toxic for embryonated eggs, the intravenous lethal dose being $0.238 \mu \mathrm{g}$ per embryo with $95 \%$ confidence limits of $0 \cdot 1-0 \cdot 7 \mu \mathrm{g}$. Batch-to-batch variation in toxicity was negligible, and the material was about five times more toxic than free endotoxin of $E$. coli for eggs of the same batch. It was pyrogenic and, after hydrolysis, 3-deoxyoctulosonate (KDO) could be detected. When injected into mice in a dose of $45 \mu \mathrm{g}$ it induced the formation of colony-stimulating factor (Quesenberry, Morley and Stohlman, 1972): sera from these mice increased the number of colonies in cultures of mouse bone-marrow cells over that in control cultures by a 
STUDIES ON NEISSERIA GONORRHOEAE

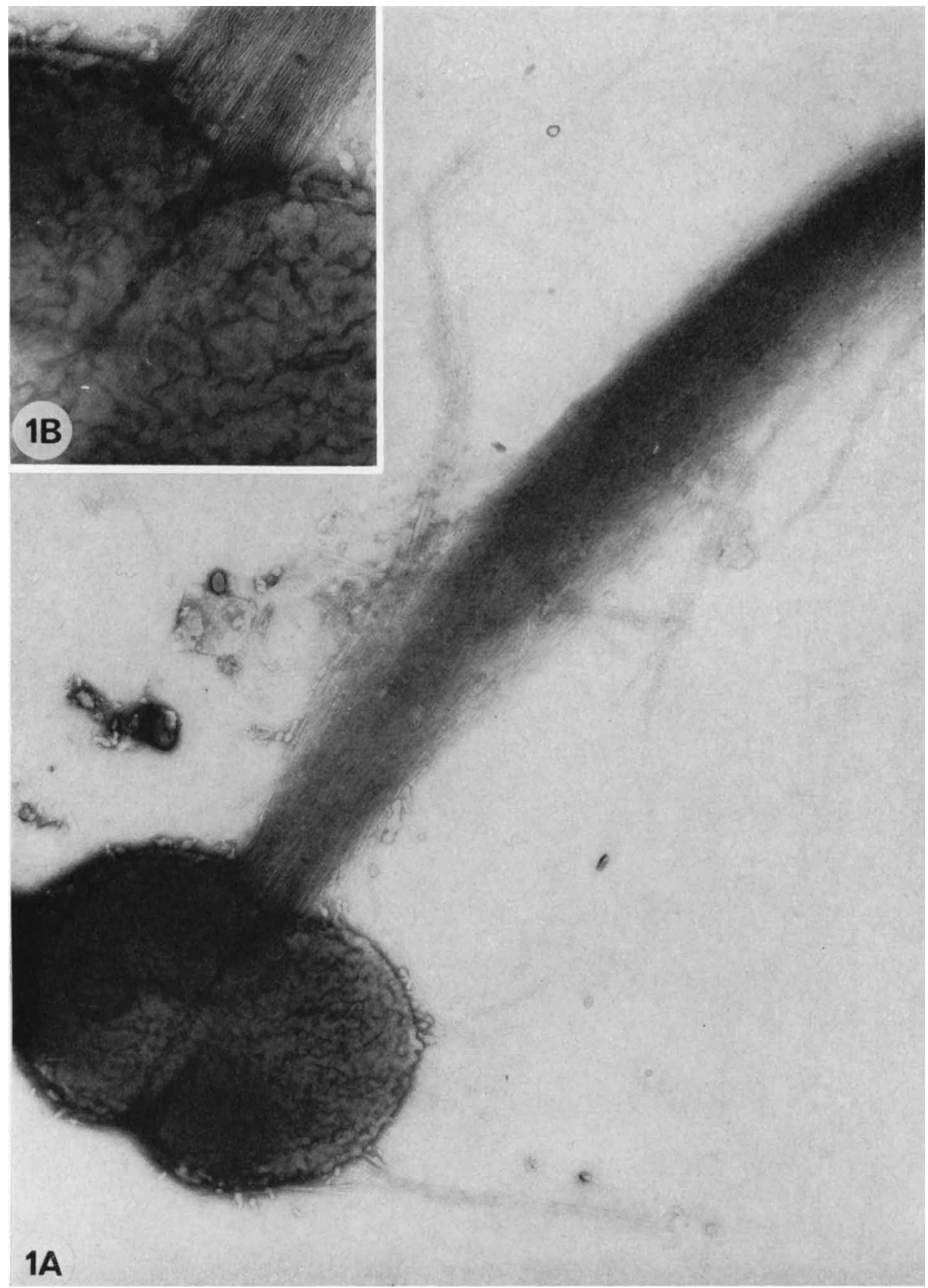

FIG. 1.-(a) Neisseria gonorrhoeae, strain Pat1, from shake-flask culture in GC medium. A sheaf of pili (c. 6- $\mu \mathrm{m}$ long) arises from the septum of a dividing cell. Note also small blebs of free endotoxin being released from the lobate surface. $\times 26,000$. (b) Detail of septum area. $\times 44,600$. Both negatively stained. 
STUdiES ON NEISSERIA GONORRHOEAE
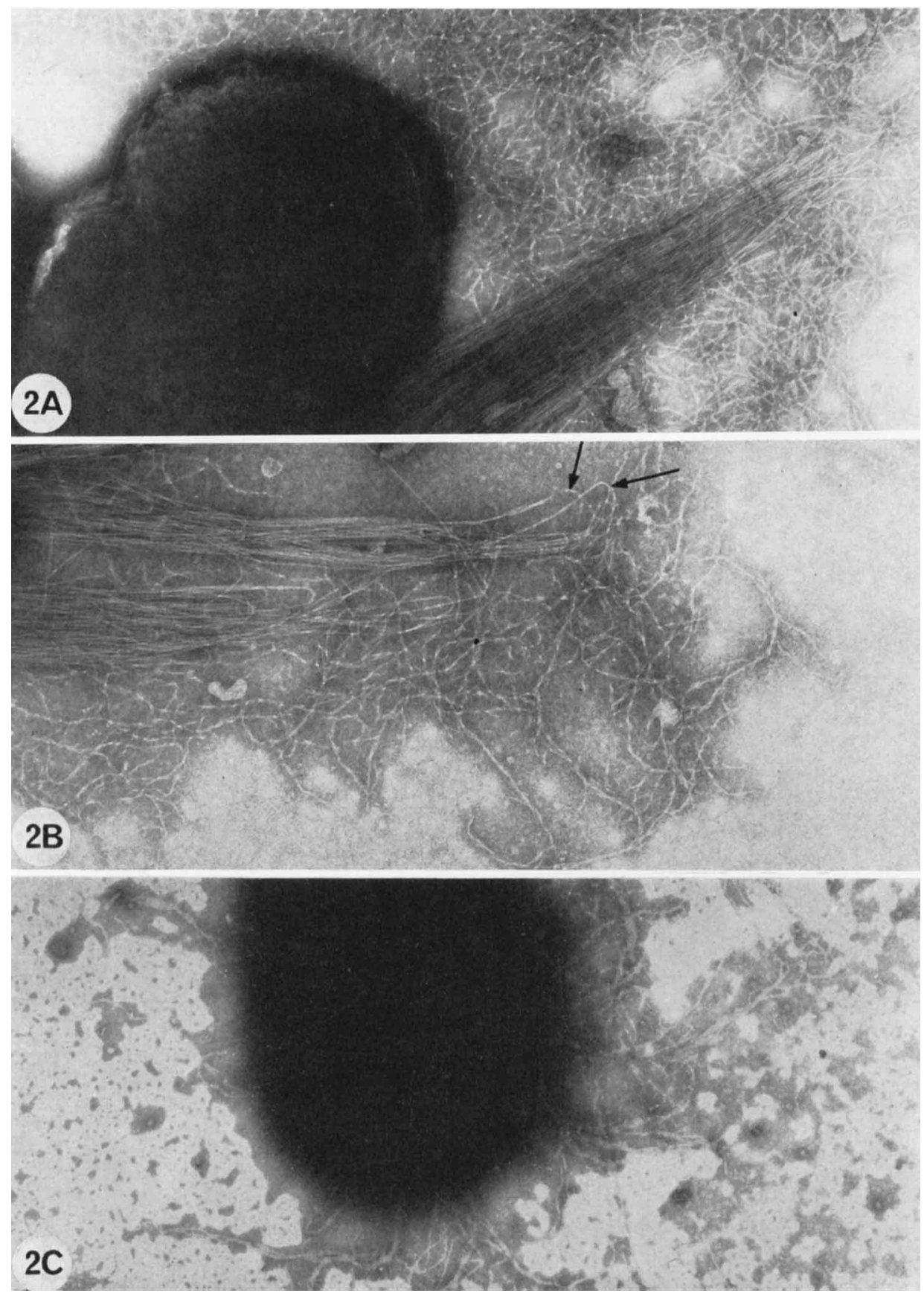

FIG. 2.- $(a)$ and $(b)$. Preparations from a shake-flask culture of strain CN6826 in GC medium. $(a)$ Type $a$ and type $b$ pili. $\times 67,000$. (b) Arrows show apparent continuation of pili $a$ into pili b. $\times 60,000$. (c) N. gonorrhoeae in urine, strain StG22, showing type-b pili. $\times 23,500$. All negatively stained. 

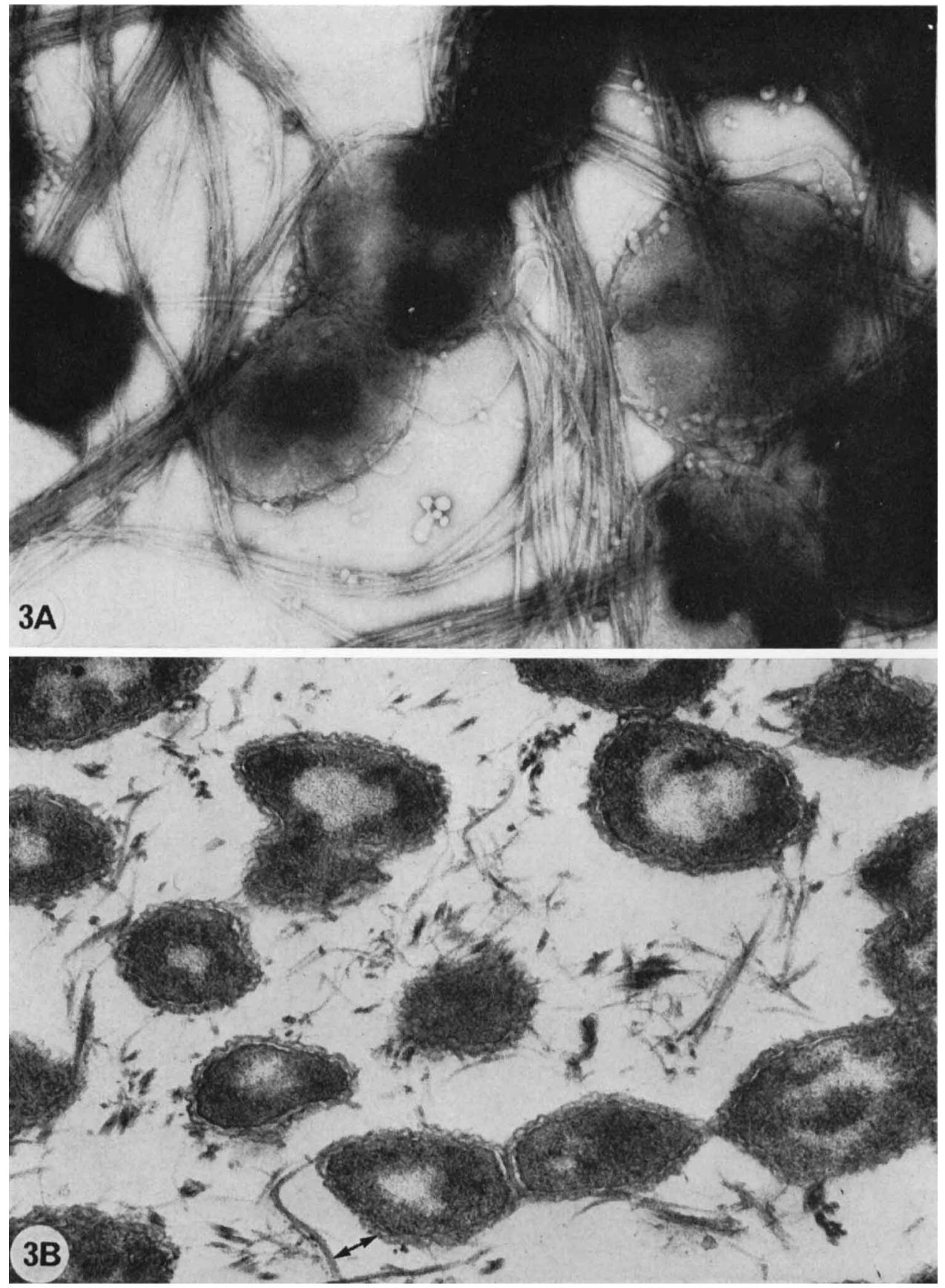

FiG. 3.-(a) $N$. gonorrhoeae, strain StG38. Cells from the first subculture on GC agar showing a large number of pili and blebs of free endotoxin. $\times 34,000$. Negatively stained. $(b)$ Ultrathin section of a colony of $N$. gonorrhoeae, strain Pat1, on GC agar showing the presence of pili and indicating a cell (arrow) from which pili have been torn off. $\times 40,000$. 
STUDIES ON NEISSERIA GONORRHOEAE
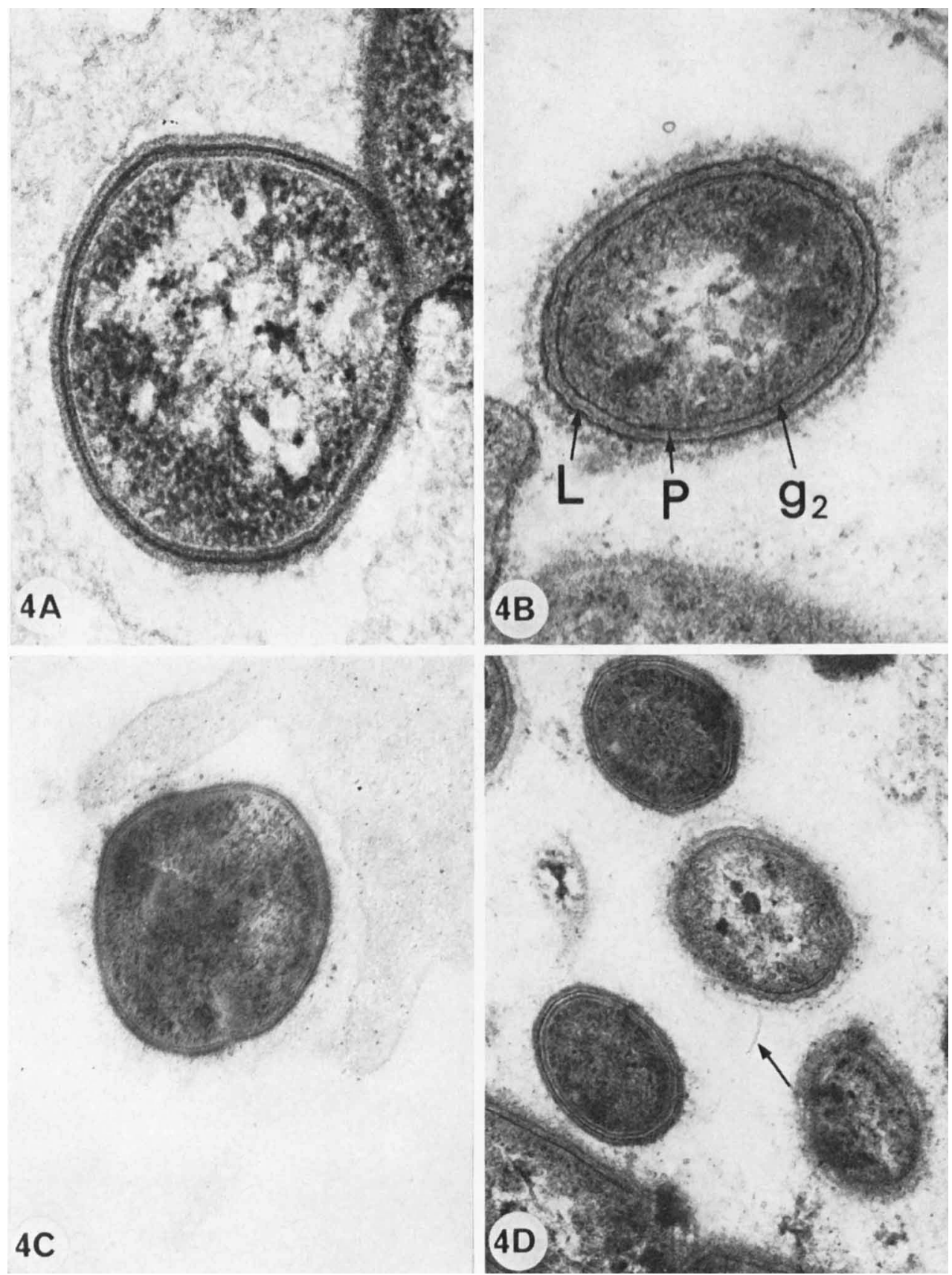

Fig. 4.-Ultrathin sections of pus: (a) N. gonorrhoeae in a phagosome. Note the smooth surface of the cell and the cell layers. $\times 124,000$. (b) $N$. gonorrhoeae in a phagosome. The trilaminar $\mathrm{L}$ layer (L), the periplasmatic space (P) and the $\mathrm{g}_{2}$ layer are illustrated. Note the fuzzy coat. $\times 117,000$. (c) N. gonorrhoeae during phagocytosis, showing the fuzzy coat extending for some distance as an appendage. $\times 40,000 .(d) N$. gonorrhoeae in a phagosome. Arrow indicates a pilus that is visible in the original. In sections of pus, pili are rarely visible. $\times 66,500$. 
STUdies ON NEISSERIA GONORRHOEAE
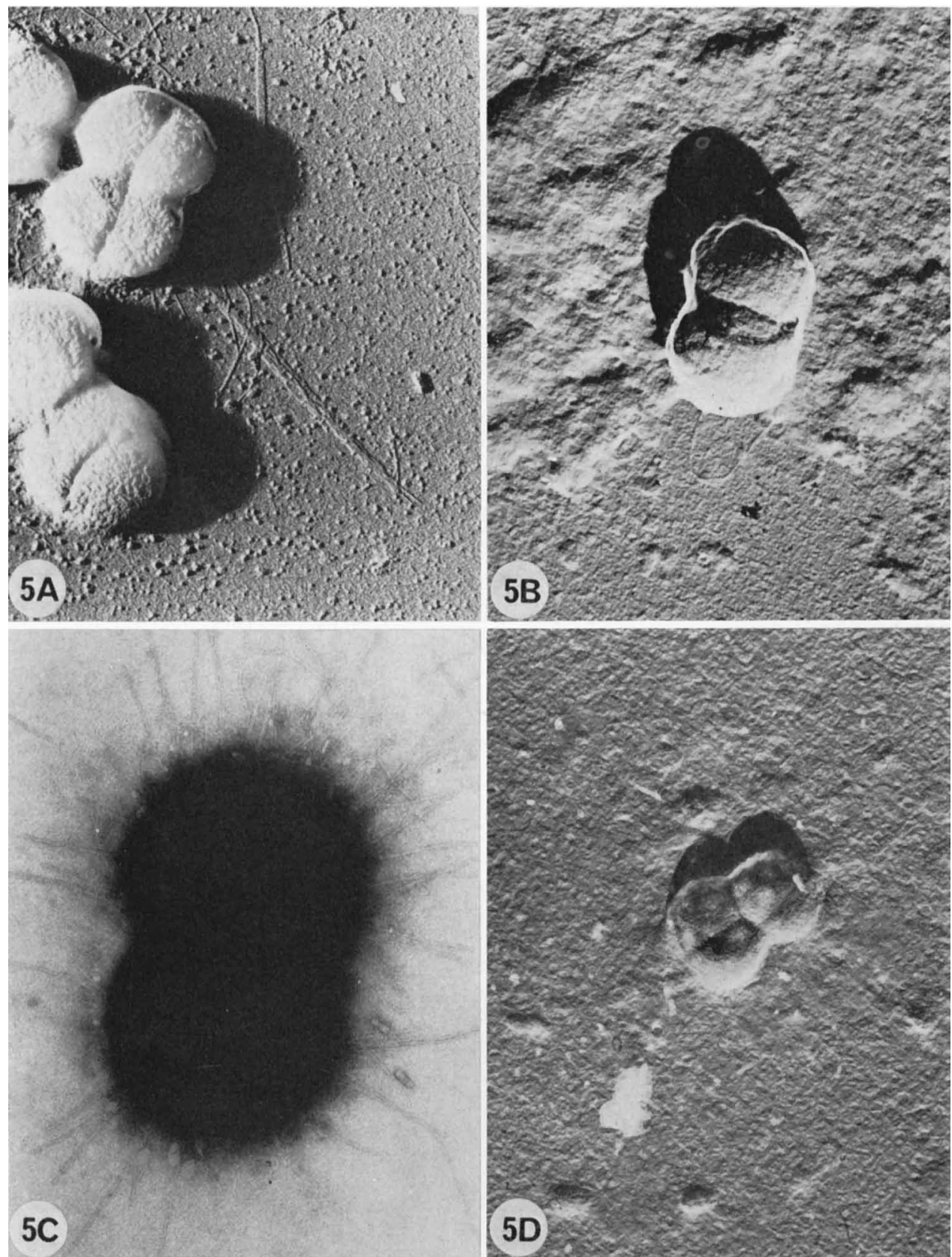

FIG. 5- - (a) N. gonorrhoeae, strain Pat1. Replica of culture on GC agar. Single pili and a bundle of pili are seen. Note the rough surface of the cells-typical of cultured cocci. $\times 20,000$. (b) Replica of pus. A single pilus can be detected. $\times 22,500$. (c) N. gonorrhoeae, strain CN6826, from GC plate showing pili around the cell. Negatively stained. $\times 39,650$. (d) Replica of pus showing a cell with smooth surface. $\times 20,000$. 
STUDIES ON NEISSERIA GONORRHOEAE
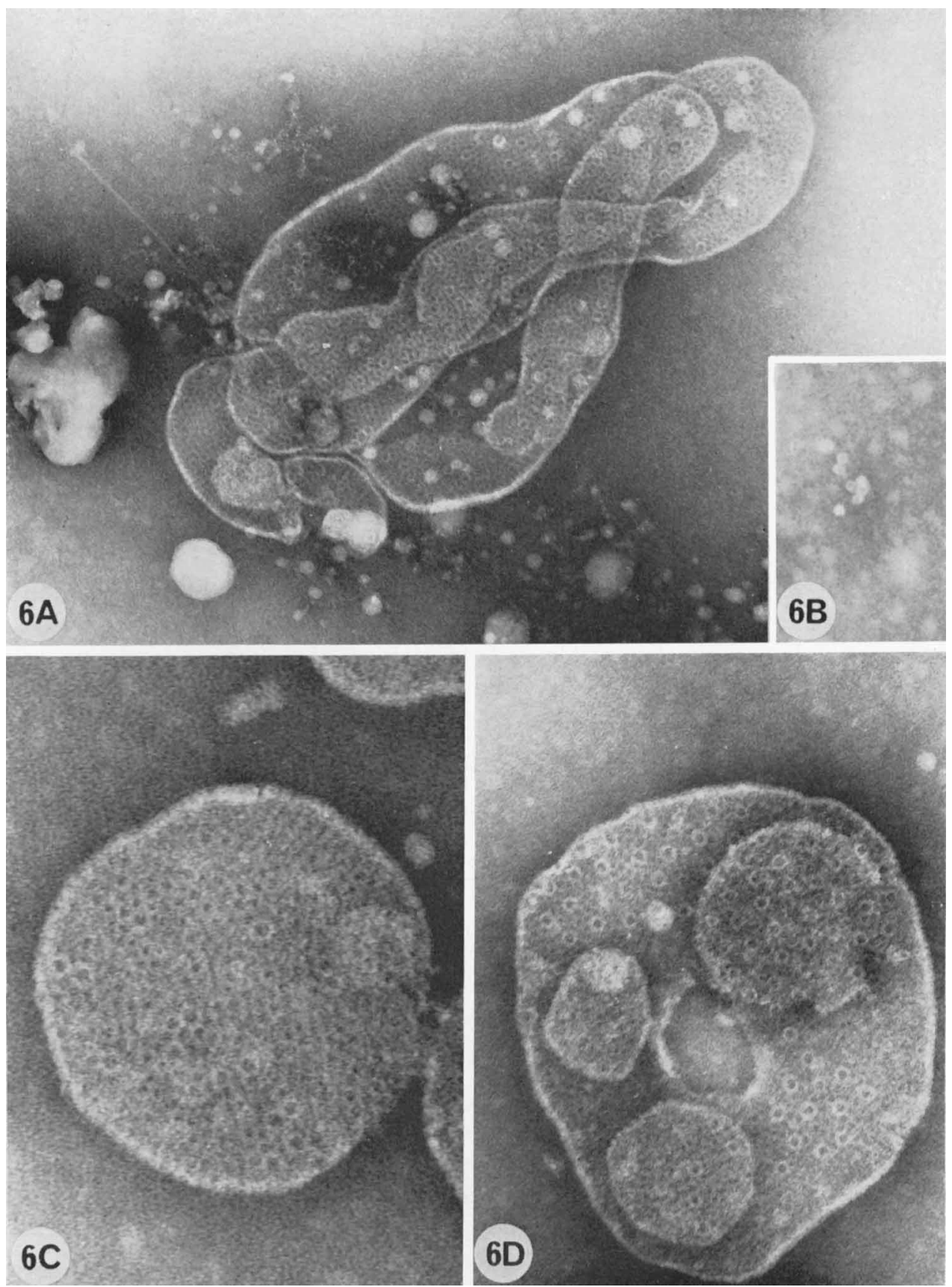

Fig. 6.-(a) Free-endotoxin bleb obtained by fractionation in the two-phase system (polyethylene glycol-methylcellulose in the presence of $0.4 \mathrm{M} \mathrm{Na}_{2} \mathrm{SO}_{4}$ ) with several folds and showing serrated appearance of the edges. $\times 124,000$. (b) Group of free ring structures. $\times 132,000$. (c) Endotoxin bleb with few ring structures left. The hexagonal pattern of the basic structure is apparent. $\times 206,000$. (d) Endotoxin bleb with ring structures regularly spaced. $\times 165,000$. All negatively stained. 

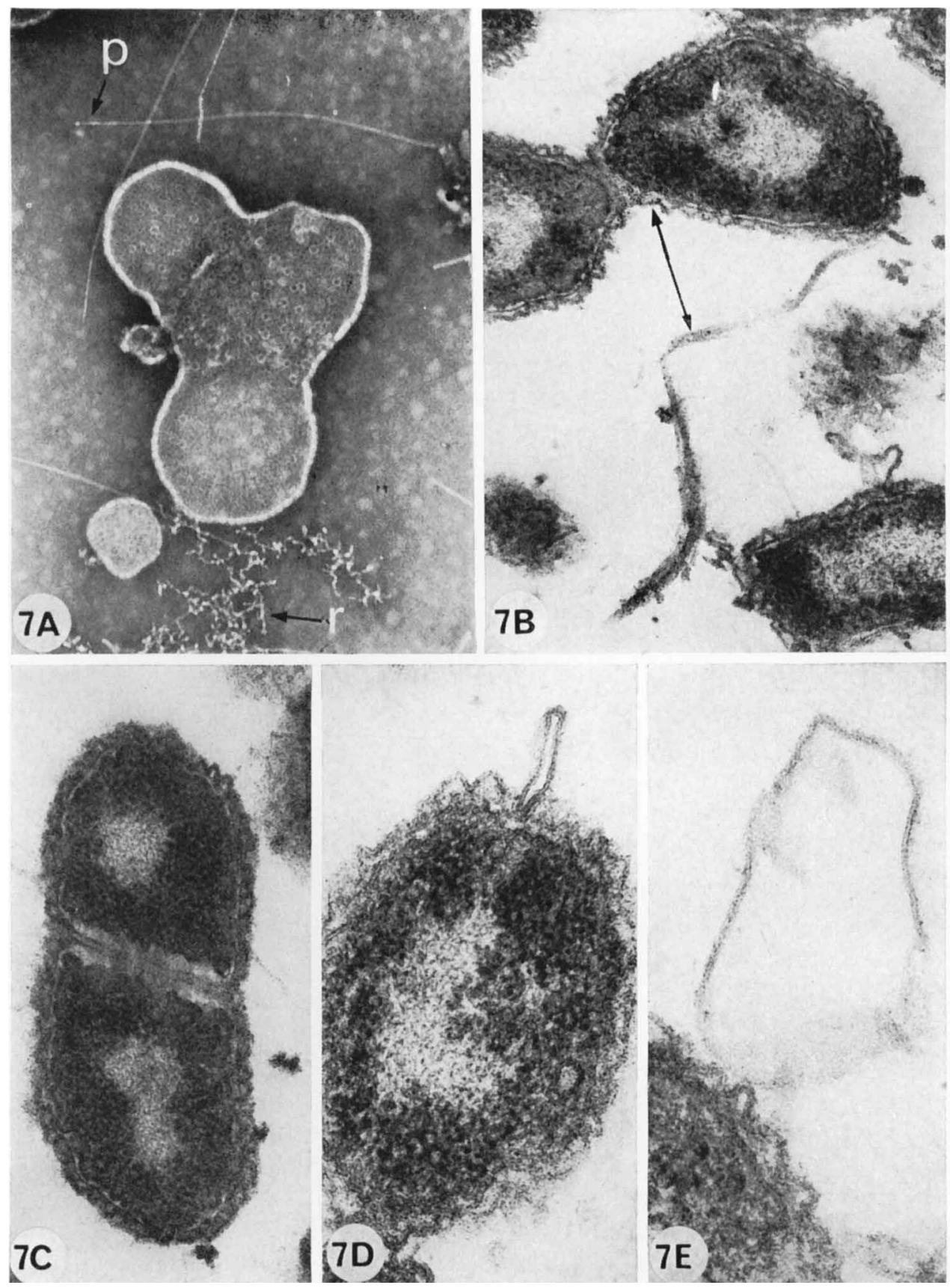

FIG. 7.-N. gonorrhoeae, strain Pat1: (a) Preparation of free endotoxin contaminated with pili type $c$ showing a knob on one end (p) and short bar structures (r). The endotoxin bleb has several folds. Negatively stained. $\times 99,000$. (b) Ultrathin section of a colony on GC agar. Arrows indicate the area of the cell from which the bundle of pili was torn. $\times 69,000$. (c) Culture from GC agar. Ultrathin section. Septum showing thick M layer. $\times 74,000$. $(d)$ Ultrathin section. Trilaminar structure of $L$ layer is seen on the cell surface as well as on the appendage. $\times 105,000$. (e) Ultrathin section from culture on GC agar showing a large apparently trilaminar section of an endotoxin bleb. $\times 131,000$. 
STUDIES ON NEISSERIA GONORRHOEAE
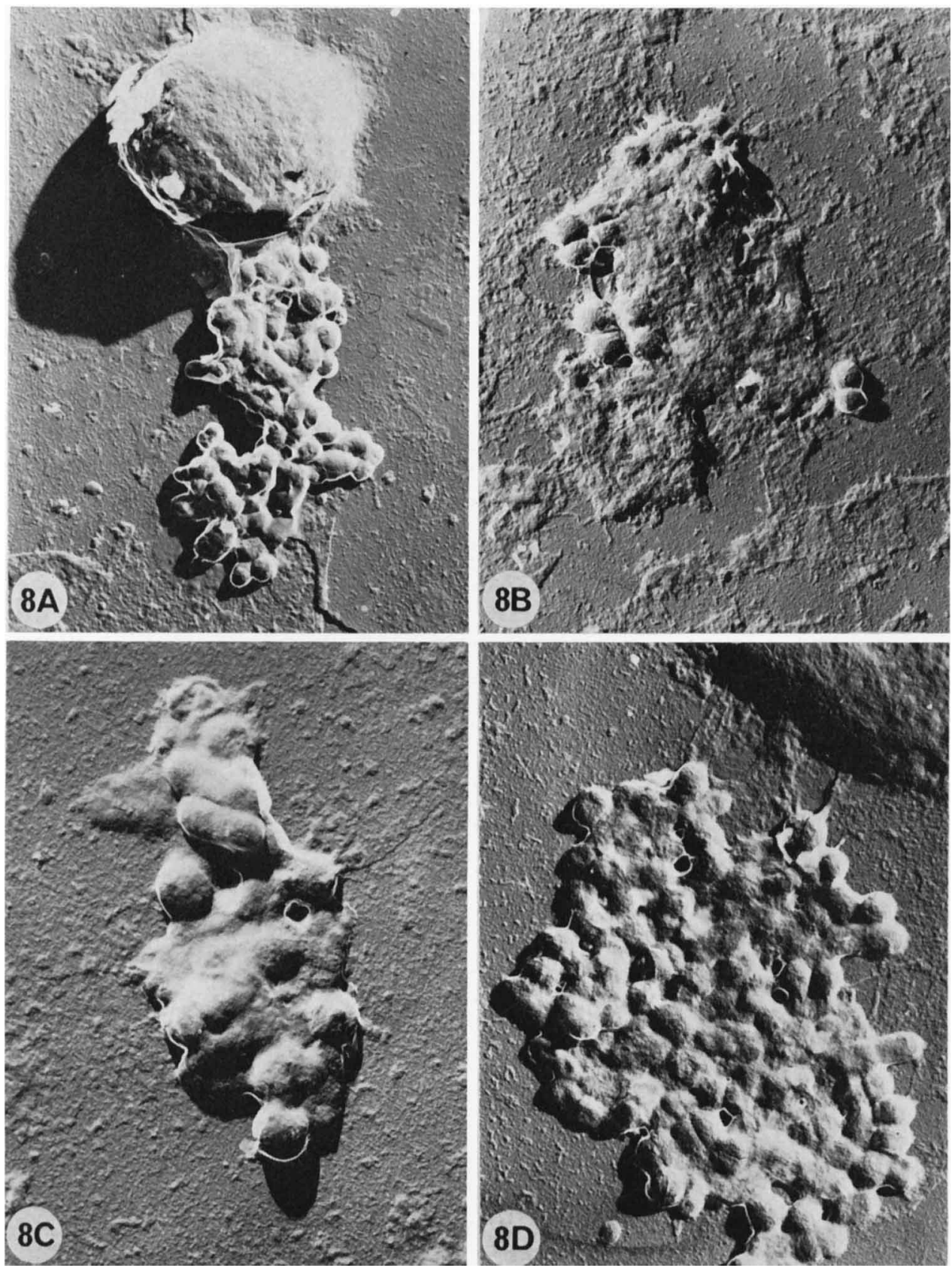

FIG. 8.-Replicas of pus. (a) A damaged phagocyte with a vesicular structure filled with gonococci separating from the nucleoplasm. $\times 4500$. (b) A vesicular remnant of a phagocyte containing a few gonococci and with free gonococci outside. $\times 6500$. (c) Small vesicle filled with gonococci. $\times 10,250$. (d) Large vesicle filled with gonococci connected by fibres to the remainder of the cell. Such clusters of multiplying gonococci are probably infectious units. $\times 8500$. 
STUDIES ON NEISSERIA GONORRHOEAE
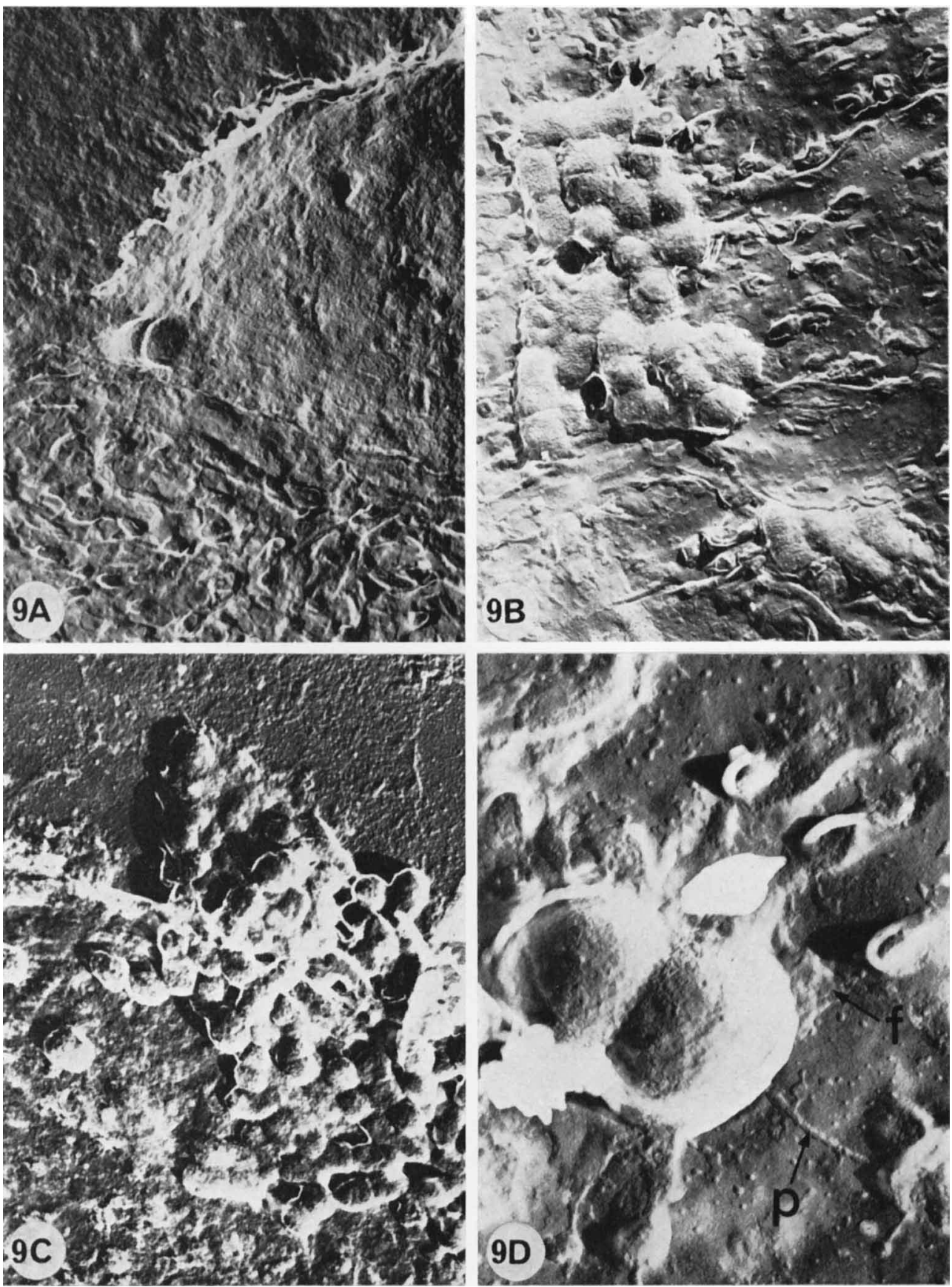

FIG. 9.-Replicas of pus. (a) A solitary gonococcus on the surface of an epithelial cell. Close contact with the host cell is apparent. $\times 10,100$. (b) A coated cluster of gonococci in the centre of an epithelial cell. $\times 10,100$. (c) Coated cluster of gonococci on the edge of an epithelial cell. $\times 6200$. (d) Solitary gonococcus on an epithelial cell, The fuzzy coat (f) and a bundle of pili (p) on the epithelial surface are indicated. $\times 35,000$. 
STUDIES ON NEISSERIA GONORRHOEAE
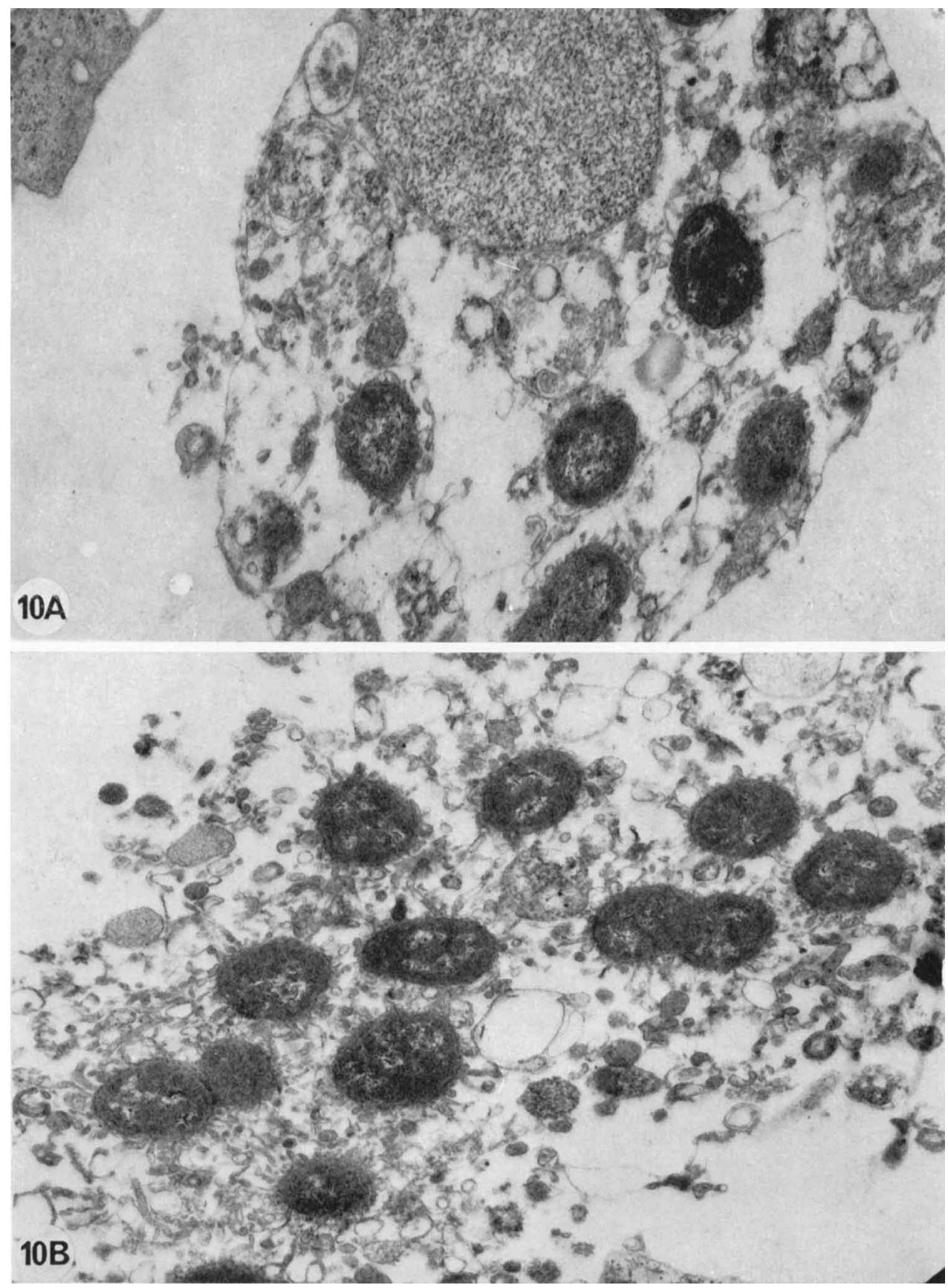

FIG. 10.-Ultrathin sections of pus. (a) Coated cluster of gonococci in a damaged phagocyte. Note accumulation of granules around some gonococci. $\times 23,500$. (b) Another example of gonococci coated with remnants of a phagocyte, indicating that they were phagocyte-borne. $\times 19,000$. 

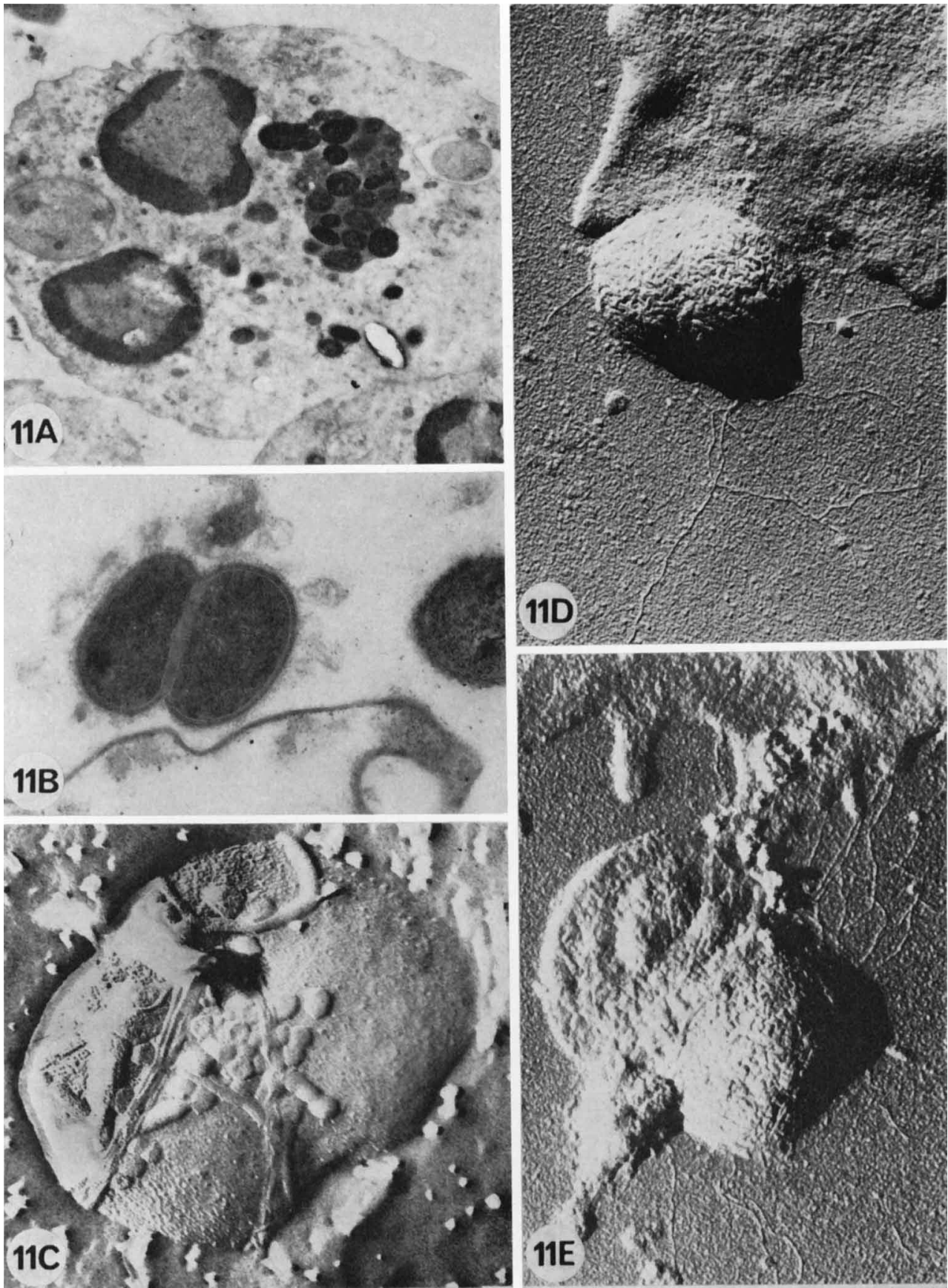

FIG. 11.-(a) Section of pus. A polymorph containing a dark vacuolar structure filled with gonococci that appear to be multiplying. $\times 8200$. $(b)$ Section of pus. Gonococcus with persisting corona of phagocyte organelles in contact with a polymorph. Note that the M layer within the septum area is of the same thickness as that of the remainder of the cell. $\times 43,000$. (c) Freezeetching of a culture of $N$. gonorrhoeae, strain CN6826. Note the bundle of pili wrapped around the surface of the cell and the presence of endotoxin blebs. $\times 54,000$. Printed as a negative. $(d)$ Replica of a culture of human amnion cells infected with $N$. gonorrhoeae, strain CN6826, showing contact of the coccus with the cell. The majority of pili are not connected to the amnion cell. $\times 28,500$. (e) Replica of a culture of human amnion cells infected with $N$. gonorrhoeae, strain CN6826. The majority of pili are connected to the amnion cell. $\times 28,500$. 
factor of eight (Dr Betty Mosedale, personal communication). Free endotoxin of $N$. gonorrhoeae behaves like endotoxin of other Gram-negative bacteria but differs from phenol-extracted lipopolysaccharide in that phenol treatment destroys most of the protein components of gonococcal endotoxin (Maeland, 1968).

Free endotoxin was present in all preparations of pili. Attempts were made to separate the endotoxin from pili with the two-phase partition systems suggested by Albertsson (1971), consisting of Dextran 500 (Pharmacia) and methylcellulose (Methocell 4000, Dow Chemical Co.) or Dextran 500 and polyethyleneglycol (Carbowax 6000) in the presence of $0.1 \mathrm{M}$ lithium phosphate or $0.4 \mathrm{M}$ sodium sulphate. With such preparations it was possible to see by electron microscopy the fine structure of the endotoxin blebs (fig. $6 a, c$ and $d$ ). In negatively stained specimens the basic lattice was hexagonal and spotted with rings with dark centres. The rings had an average internal diameter of $6.7 \mathrm{~nm}$ and outer diameter of $11.7 \mathrm{~nm}$. The mean distance between the ring structures when they were distributed in a regular pattern was $26 \mathrm{~nm}$. The inner radius of the hexagons of the endotoxin matrix was 3.3-4 nm; these measurements were calculated from several micrographs, where the edge of a bleb was serrated (fig. $6 a$ and $c$ ), assuming that the serration was determined by the dimensions of the hexagons.

\section{The interaction between gonococci and host cells}

Several types of interaction between gonococci and host cells could be seen on electron micrographs of urethral exudates. In replicas it appeared that a fuzzy layer of the coccus had slipped from the cell surface and was lying in contact with the host cell. Thus, close contact between gonococci and host cells was possible without the apparent involvement of pili, although on the rare occasions when pili could be seen they lay with the fuzzy layer on the epithelial cell surface (fig. $9 d$ ).

Examination of Gram-stained smears of epithelial cells from infected urethra reveals the presence of many gonococci associated with them. Studies with the electron microscope showed that these clusters of gonococci were coated with a layer of material of variable thickness that concealed the surface of individual cocci within the cluster. When the cluster was near the middle of an epithelial cell it was difficult to decide whether or not the cocci had penetrated the surface of the host cell (fig. 9b). When the cluster was on the edge of the epithelial cell, it was evident that it was enclosed in a sac (fig. 9c).

In ultrathin sections of pus most gonococci were seen to be intracellular. The number of gonococci per phagocyte varied considerably from one per cell to as many as 80 in one section plane. Some of these were intact, with wellorganised wall layers and nucleoplasm, and appeared to have recently been phagocytosed (fig. $4 a$ ), but the majority were being digested. The bacterial cell wall was the part most resistant to the lytic process. All intracellular organisms were contained in vacuoles (phagosomes) and some of these contained several cells. In these phagosomes the membrane was not in close contact with the cocci and appeared to be active. Some vacuoles, however, were packed with organisms, some of which had cross-walls, as though actively dividing. In these vacuoles there was no space between the cocci and the membrane, and there was no indication that destruction of the organisms was taking place 
(fig. 11a). A number of sections revealed the presence of dead polymorphs, some completely lysed with freed cocci surrounded by granules or organelles (fig. 10b). In other sections, the phagocyte membrane remained (fig. 10a). The cocci from these destroyed polymorphs seemed intact and appeared normal.

Evidence for the destruction of phagocytes could be seen in replicas. Fig. $8 a$ illustrates partial separation of the nucleus from the remainder of a phagocyte which forms a vesicle containing gonococci. On some vesicles nucleoplasm could not be seen (fig. $8 b$ ), whilst other vesicles were still connected by fibrils to the nucleoplasm (fig. 8d). Some of these vesicles were clearly associated with phagocytes (fig. $8 a$ and $d$ ), whereas others were free, as seen in fig. $8 b$ and $c$. Most of the clusters of gonococci present in urethral exudates were inside vesicles of this kind and were of variable size (fig. $8 b, c$ and $d$ ).

\section{Discussion}

These results clearly indicate that the morphology of gonococci grown under natural conditions, i.e., intra-urethrally, differed from that of cocci grown in vitro even in primary cultures. The former appeared round and smooth, whereas cultured cells had irregular surfaces irrespective of the type of medium or the methods that we used. They appeared rough in replica preparations, convoluted on negative staining or lobate on thin-sectioning. The lobate surface of cultured gonococci was observed in sections and freeze-etched preparations by Swanson (1972) and with the scanning electron microscope by Kraus and Glassman (1974). A similar surface structure has been reported in cultured meningococci (de Voe and Gilchrist, 1973) in Veillonella alcalescens (Bladen, Gewurz and Mergenhagen, 1967) and in other Gram-negative organisms (de Petris, 1967). However, we know of no report of the striking differences between the surface structure of cultured and natural gonococci that we observed.

Another marked difference concerns the concentration of pili, which were rarely seen in infected urethral exudates or on naturally occurring cocci but were normally present in $\mathrm{T} 1$ and $\mathrm{T} 2$ colonies obtained from primary cultures. Here their number varied considerably from a few per colony to such large numbers that the gonococci were embedded in a meshwork of them (fig. 3a). Since the primary cultures consisted of the virulent colonial types $\mathrm{T} 1$ and $\mathrm{T} 2$, it must be presumed that the cells from which the colonies were derived were also virulent.

The reasons for the variation in the type and degree of piliation in $\mathrm{T} 1$ and $\mathrm{T} 2$ cells are not clear. Pili $c$ having a knob on one end morphologically resemble the sex pili of $E$. coli (Lawn and Meynell, 1970). If they really are sex pili, the variability in piliation would be determined by a regulatory mechanism.

On the other hand, pili $a$ may be a part of the cell wall. They may be wrapped round the cell, as suggested by Swanson (1972) (fig. 11c), and such pili would become detached if the cell surface was altered. This possibility is illustrated in figs. $3 b$ and $7 b$, where it can be seen that the shape of pili fits the contours of the organisms from which they have presumably become detached.

Another explanation is that the appearance of pili may be connected with the disorganisation of the cell layers that occurs under unfavourable growth conditions and has already been described. It is to be expected that this disorganisation would lead to abnormal cell division. 
Large bundles of pili are frequently seen as outgrowths from the area of cross-wall formation (fig. $1 a$ and $b$ ). Swanson (1972) observed that pili appeared to "eminate from the depths of the seams " in freeze-etched preparations. The $M$ layer may be more than $20 \mathrm{~nm}$ thick in the cross-wall (fig. 7c), and cells after division may be connected by so-called zones of adhesion (Swanson et al., 1971). Neither of these phenomena is seen in pus, and the heavy piliation found may possibly be connected in some way with a disorganised surface structure or abnormal division, or both. Under such conditions, an integral protein of the cell wall might arise as an atypical form and be over-produced when incorporation into its normal functional position was not possible. This view is supported by the fact that rabbits immunised with non-piliate T3 cells gave rise to antibodies reacting with type $a$ pili from homologous T2 cells (Turner and Novotny, 1974; Novotny and Turner, 1975).

Unfortunately, efforts to isolate pure pili in order to determine their composition have so far been unsuccessful. Using Brinton's technique (1965) we found that although they were aggregated by $0 \cdot 1 \mathrm{M} \mathrm{MgCl}_{2}$, they precipitated from suspensions along with free endotoxin. Indeed, suspensions of free endotoxin could be precipitated with this solute in the absence of pili. Free endotoxin detected either by electron microscopy or by biological testing was, therefore, present in all our preparations of pili. Pictures of pili (Swanson et al., 1971) or purified pili (Punsalang and Sawyer, 1973) also show the presence of free endotoxin.

Current thinking on the pathophysiology of gonorrhoea implies that attachment of virulent organisms to the host cells is facilitated by pili (Punsalang and Sawyer, 1973; Thongthai and Sawyer, 1973; Ward, Watt and Robertson, 1974) or that pili are the "first component or type of attachment" of gonococci to amnion cells (Swanson, 1973). Although examples of the apparent involvement of pili in attachment to tissue-culture cells could be demonstrated, there were numerous examples of attachment that did not appear to be mediated in this way; these "exceptions" are in accordance with our observation of the relative absence of pili under natural conditions.

Attachment of gonococci to tissue-culture cells can be inhibited by antisera against $\mathrm{T} 2$ but not $\mathrm{T} 4$ cells, and this suggests that specific factors associated with type T2 cells are involved. On the other hand, Arko et al. (1974) showed that a vaccine prepared from $\mathrm{T} 2$ cultures of an avirulent strain could protect chimpanzees against the homologous virulent strain, implying that the protective activity of an antigenic preparation does not invariably reflect that it contains all of the factors responsible for virulence.

The basic structure of free endotoxin seen in partially lysed cells, in endotoxin blebs treated with salt solution or after fractionation in two-phase partition systems, is similar to that observed in Bordetella pertussis, Fusiformis nodosus (unpublished observation), in Tetrahymena ciliary membranes (Bittman, Chen and Anderson, 1974), and in $V$. alcalescens after complement treatment (Bladen et al., 1967). Its general arrangement is in agreement with proposed models of the structure of cell membranes (Singer and Nicolson, 1972; Costerton, Ingram and Cheng, 1974). Ring structures were seen by Swanson et al. (1971) and Swanson (1972) in negatively stained preparations of $N$. gonorrhoeae and after freezeetching. We have seen that these rings often appeared in a regular pattern (fig. $6 d$ ). In some blebs or in areas of the same bleb, however, the distance between the rings varied. This occurred when the bleb was folded (figs. $6 a$ and $7 a$ ). Since we were able to find similar ring structures free or clumped together (fig. $6 b$ ) it may be assumed that some of them had 
become detached from the basic lattice. Whether the rings are dislodged by a physical or autolytic process is not known. They do not represent holes in the lattice. Their dark centres could be due to deposits of negative stain. The fine structure described could not be seen on intact cell surfaces or on freshly isolated free endotoxin, and this suggests that it was masked by a coating outside the $L$ layer. This coat and extensions of it may be represented by the fuzz seen on sections of gonococci from pus. The function or composition of this coat is not understood and it would be premature to suggest that it had any connexion with virulence.

Studies of replica preparations of urethral pus revealed that the gonococci were usually present as clusters of variable size inside vesicular membranes which were either free or attached to epithelial cells. It is suggested that these membranes are the remnants of dead phagocytes in which gonococci have multiplied. The number of gonococci that can be ingested by a phagocyte is variable but under suitable conditions a hundred may be taken up. Most of these are killed and digested (Ward, Glynn and Watt, 1972), but the polymorphs do not have the ability to regenerate, and it is likely that some die before the process of destroying the gonococci has been completed. Under such conditions the few surviving gonococci may start to multiply. There would be no shortage of nutrients; the phagocytes contain a digest of bacteria and autodigest, and it is likely that the surviving and multiplying gonococci would be protected from the humoral defence system. Similar observations have been made by de Voe, Gilchrist and Storm (1973) who investigated the phagocytosis of meningococci in vitro. Many of the leukocytes were lysed and the meningococci were released into the medium enclosed within membranous sacs, probably phagosomes.

If the cocci do multiply in the vesicles, is it necessary for them to be released in order to invade the host cells; or is the coated cluster itself an infectious unit ? The latter alternative is a possibility, because clusters are seen on epithelial cells. Of course, free gonococci may be infectious, but clusters of multiplying cocci may present special challenges to host defence systems. It is possible that the clusters of cocci seen in some polymorphs (fig. 11a) have actually been phagocytosed as small coated clusters.

In many sectioned phagocytes containing gonococci there was almost complete degranulation, but degranulation was far from complete in some and, indeed, may have been inhibited. Organisms that had survived phagocytosis had a corona of granules and organelles closely arranged around them (fig. 10a and $b$ ). This corona persisted on some gonococci after they had been freed from the lysed phagocyte and they were thus labelled as "phagocyte-borne" (fig. 11b). Similar coronas can be seen around gonococci in the micrographs of urethral scrapings published by Ward and Watt (1972) and this suggests that the gonococci in close contact with epithelial cells were most probably " phagocyte-borne". Phagocytosis and digestion of bacteria is a complex sequential process (Windhorst, 1970). The stage of phagosome formation appeared normal, but our evidence suggests that ingested organisms interfered with one or more of the later stages.

In the pathogenesis of gonorrhoea, the phagocytes clearly play an important 
role. As well as being involved in the primary defence mechanism, phagocytosis seems to be responsible for the maintenance of infectious units in the urethra.

\section{SUMMARY}

Electron-microscope studies are reported in which gonococci grown in cultures are compared with those present in urethral exudates. Whereas naturally occurring cells presented a smooth appearance with parallel cell layers, cultured cells were rough and their surface layers appeared to be disorganised. Three different types of pili were observed in cultures; the most common type seemed to be a product of unfavourable growth conditions. The number of piliate cells in pus was variable but always much lower than the number of non-piliate cells found. A study of free endotoxin present in cultures was made and its fine structure is described.

Further observations suggest that although the majority of gonococci are killed after phagocytosis, others survive and multiply-giving rise to clusters of gonococci within remnants of phagocytes. It is suggested that these coated clusters are infectious units.

We wish to thank Dr R. O. Thomson for his help in preparing the manuscript, Dr C. S. Ratnatunga and Dr D. Wright for help in obtaining pus from male patients with gonorrhoea, Dr J. Milerova for titration of free endotoxin preparations on embryonated eggs, Miss $\mathbf{N}$. Yeoell for pyrogenicity tests, and Miss S. Kennett, Mr C. Gilson and Mr P. Hine for invaluable technical assistance.

\section{REFERENCES}

Albertsson, P. A. 1971. Partition of cell particles and macromolecules, 2nd ed., London, p. 74.

ARKo, R. J. 1972. Neisseria gonorrhoeae: experimental infection of laboratory animals. Science N.Y., 177, 1200.

ARKo, R. J. 1973. Implantation and use of a subcutaneous culture chamber in laboratory animals. Lab. Anim. Sci., 23, 105.

ARKo, R. J. 1974. An immunological model in laboratory animals for the study of Neisseria gonorrhoeae. J. infect. Dis., 129, 451.

Arko, R. J., Kraus, S. F., Brown, W. J., Buchanan, T. M. and Kuhn, U. S. G. 1974. Neisseria gonorrhoeae: effect of systemic immunisation on resistance of chimpanzees to urethral infection. J. infect. Dis., 130, 160.

Bladen, H. A., Gewurz, H. and Mergenhagen, S. E. 1967. Interactions of the complement system with the surface and endotoxic lipopolysaccharide of Veillonella alcalescens. J. exp. Med., 125, 767.

Bittman, R., Chen, W. C. ANd Anderson, O. R. 1974. Interaction of Filipin III and amphotericin B with lecithin-sterol vesicles and cellular membranes. Spectral and electron microscope studies. Biochemistry, N.Y., 13, 1364.

BradLEY, D. E. 1954. Evaporated carbon films for use in electron microscopy. Br. $J$. appl. Phys., 5, 65.

BRINTON, C. C. JR 1965. The structure, function, synthesis and genetic control of bacterial pili and a molecular model for DNA and RNA transport in Gram negative bacteria. Trans. N.Y. Acad. Sci., 27, 1003.

Buchanan, T. M. AND Gotschlich, E. C. 1973. Studies on gonococcus infection. III. Correlation of gonococcal colony morphology with infectivity for the chick embryo. J. Exp. Med., 137, 196. 
Bumgarner, L. R. And Finkelstein, R. A. 1973. Pathogenesis and immunology of experimental gonococcal infection: virulence of colony types of Neisseria gonorrhoeae for chicken embryos. Infect. Immun., 8, 919.

Costerton, J. W., INGRAM, J. M. AND ChENG, K. J. 1974. Structure and function of the cell envelope of Gram negative bacteria. Bact. Rev., 38, 87.

Crutchley, M. J., Marsh, D. G. AND Cameron, J. 1967. Free endotoxin. Nature, Lond., 214, 1052.

DifCO MANUAL OF DEHYDRATED CULTURE MEDIA AND REAGENTS FOR MICROBIOLOGICAL AND CLINICAL labORATORY PROCEDURES, 1971. 2nd ed., Detroit, pp. 122-123.

Duguid, J. P., ANDERson, E. S. AND CAMPBell, I. 1966. Fimbriae and adhesive properties in Salmonellae. J. Path. and Bact., 92, 107.

Elbein, A. D. AND Heath, E. C. 1965 . The biosynthesis of cell wall lipopolysaccharide in Escherichia coli. I. The biochemical properties of a uridine diphosphate galactose 4-epimeraseless mutant. J. biol. Chem., $240,1919$.

Ellen, R. P. AND Gibbons, R. J. 1972. M protein-associated adherence of Streptococcus pyogenes to epithelial surfaces: pre-requisite for virulence. Infect. Immun., 5, 826.

Ghalambor, M. A., Levine, E. M. AND Heath, E. C. 1966 . The biosynthesis of cell wall lipopolysaccharide in Escherichia coli. III. The isolation and characterisation of 3-deoxyoctulosonic acid. J. Biol. Chem., 241, 3207.

Glauert, A. M. and Glauert, R. H. 1958. Araldite as an embedding medium for electron microscopy. J. biophys. biochem. Cytol., 4, 191.

Hirsch, J. G. AND Corn, Z. A. 1960. Degranulation of polymorphonuclear leucocytes following phagocytosis of micro-organisms. J. Exper. Med., 112, 1005.

JephCOTt, A. E., Reyn, A. AND BIRCh-ANDERSEN, A. 1971. Neisseria gonorrhoeae. III. Demonstration of presumed appendages to cells from different colony types. Acta path. microbiol. scand., B79, 437.

Kellenberger, E., RYTer, A. AND Stchaud, J. 1958. Electron microscope study of DNA containing plasms. II. Vegetative and mature phage DNA as compared with normal bacterial nucleoids in different physiological states. J. biophys. biochem. Cytol., 4, 671 .

KellogG, D. S. JR, Cohen, I. R., Norins, L. C., Schroeter, A. L. AND Reising, G. 1968. Neisseria gonorrhoeae. II. Colonial variation and pathogenicity during 35 months in vitro. J. Bact., 96, 596.

Kellogg, D. S. JR, Peacock, W. L. Jr, Deacon, W. E., Brown, L. and Pirkle, C. I. 1963. Neisseria gonorrhoeae. I. Virulence genetically linked to clonal variation. J. Bact., 85, 1274.

KellogG, D. S. JR AND TURNER, E. M. 1973. Rapid fermentation confirmation of Neisseria gonorrhoeae. Appl. Microbiol., 25, 550.

Kenny, C. P., Diena, B. B., Wallace, R. and Grenberg, L. 1972. Cultivation and properties of Neisseria species grown in chemically defined media. Can.J. Microbiol., 18, 1087.

Kraus, S. J. and Glassman, L. H. 1974. Scanning electron microscope study of Neisseria gonorrhoeae. Appl. Microbiol., $27,584$.

Lawn, A. M. and Meynell, E. 1970. Serotypes of sex pili. J. Hyg., Camb., 68, 683.

Lucas, C. T., Chandler, F. JR, Martin, J. E. JR and Schmale, J. D. 1971. Transfer of gonococcal urethritis from man to chimpanzee. An animal model for gonorrhoea. J. Am. med. Ass., 216, 1612.

MAELAND, J. A. 1968. Antigenic properties of various preparations of Neisseria gonorrhoeae endotoxin. Acta path. microbiol. Scand., 73, 413.

MoOR, H., Mühlethaler, K., Waldner, H. ANd Frey-Wyssling, A. 1961. A new freezing ultramicrotome. J. biophys. biochem. Cytol., $10,1$.

NOVOTNY, P. AND TURNER, W. H. 1975. Immunological heterogeneity of pili of Neisseria gonorrhoeae. J. gen. Microbiol., 89, 87.

OfEK, I., BeAChEY, E. H. AND BISNo, A. L. 1974. Resistance of Neisseria gonorrhoeae to phagocytosis: relationship to colonial morphology and surface pili. J. infect. Dis., 129, 310. 
Palade, G. E. 1952. A study of fixation for electron microscopy. J. exp. Med., 95, 285.

PETRIS, S. DE 1967. Ultrastructure of the cell wall of Escherichia coli and chemical nature of its constituent layers. Journal of Ultrastruct. Res., 19, 45.

Punsalang, A. P. AND SawYer, W. D. 1973. Role of pili in the virulence of Neisseria gonorrhoeae. Infect. Immun., 8, 255.

Quesenderry, P., Morley, A., Stohlman, F. JR, Rickard, K., Howard, D. and Smith, M. 1972. Effect of endotoxin on granulopoeisis and colony-stimulating factor. New Engl. J. Med., 286, 227.

Reynolds, E. S. 1963. The use of lead citrate at high $p \mathrm{H}$ as an electron opaque stain in electron microscopy. J. Cell Biol., 17, 208.

Sabatini, D. D., Bensch, K. AND BarRnetT, R. J. 1963. Cytochemistry and electron microscopy. The preservation of cellular ultrastructure and enzymatic activity by aldehyde fixation. J. Cell Biol., 17, 19.

Singer, S. J. AND Nicolson, G. L. 1972. The fluid mosaic model of the structure of cell membranes. Science, N.Y., 175, 720.

Swanson, J. 1972. Studies on gonococcus infection. II. Freeze-fracture, freeze-etch studies of gonococci. J. Exp. Med., 136, 1258.

Swanson, J. 1973. Studies on gonococcus infection. IV. Pili: their role in attachment of gonococci to tissue culture cells. J. exp. Med., 137, 571.

Swanson, J., Kraus, S. J. AND Gotschlich, E. C. 1971. Studies of gonoccocus infection. I. Pili and zones of adhesion: their relation to gonococcal growth patterns. J. exp. Med., 134, 886.

Thomas, D. W., Hill, J. C. AND Tyeryar, F. J. JR 1973. Interaction of gonococci with phagocytic leukocytes from men and mice. Infect. Immun., 8, 98.

ThongthaI, C. AND SAWYER, W. D. 1973. Studies on the virulence of Neisseria gonorrhoeae. I. Relation of colonial morphology and resistance to phagocytosis by polymorphonuclear leukocytes. Infect. Immun., 7, 373.

TURNER, W. H. AND NovotNY, P. 1974. Immune electron microscopy of pili from Neisseria gonorrhoeae. Proc. Soc. gen. Microbiol., 2, 18.

VOE, I. W. DE AND GILCHRIST, J. E. 1973. Release of endotoxin in the form of cell wall blebs during in vitro growth of Neisseria meningitidis. J. exp. Med., 138, 1156.

VOE, I. W. DE, GILCHRIST, J. E. AND STORM, D. W. 1973. Ultrastructural studies on the fate of group B meningococci in human peripheral blood leukocytes. Can.J. Microbiol., 19, 1355 .

WINDHORST, D. B. 1970. Functional defects of neutrophils. Adv. intern. Med., 16, 329.

WARD, M. E., GLYNN, A. A. AND WATT, P. J. 1972. The fate of gonococci in polymorphonuclear leucocytes: an electron microscopic study of the natural disease. Br.J. exp. Path., 53, 289.

WARD, M. E. AND WATT, P. J. 1972. Adherence of Neisseria gonorrhoeae to urethral mucosal cells: an electron microscopic study of human gonorrhoea. J. infect. Dis., 126, 601.

Ward, M. E., WatT, P. J. AND Robertson, J. N. 1974. The human fallopian tube: a laboratory model for gonococcal infection. J. infect. Dis., 129, 650. 